\title{
Pandemic Language Teaching: Insights from Brazilian and International Teachers on the Pivot to Emergency Remote Instruction
}

\author{
Ana Sevilla-Pavón', Kyria Rebeca Finardi² \\ ${ }^{1}$ IULMA/Universitat de València, Spain \\ ${ }^{2}$ Universidade Federal do Espírito Santo, Brazil \\ Correspondence concerning this article should be addressed to Kyria Rebeca Finardi, Federal University \\ of Espírito Santo, Av. Fernando Ferrari, 514, postcode 29075910. Goaibeiras, Vitória, Espírito Santo, Brazil. \\ E-mail: kyria.finardi@gmail.com

\begin{abstract}
This article reflects on the experiences of language teachers from Brazil, Spain, France, Cyprus, Costa Rica and Taiwan during the pivot to emergency remote/online instruction during the 2020 pandemic. The research question motivating the study was what language teachers' perceptions regarding online teaching during the pandemic were. Data were analyzed qualitatively, contrasting data from a questionnaire shared in an asynchronous online form with data from focus group interviews carried out via videoconferencing. The analysis of the questionnaire data showed that the vast majority of respondents used different digital technologies to teach online, both synchronously and asynchronously, but felt unprepared to work in this modality, mostly because of lack of institutional support and training. The analysis of the focus group interviews suggested that most teachers expressed concerns as to the limitations of online teaching for interaction and exams. In addition, some teachers displayed negative attitudes towards online teaching due to the lack of preparation and institutional support. This was aggravated by political implications of migrating to online education that could result in precariousness of the teacher profession. The positive aspects highlighted were the possibility of developing more self-directed and autonomous learning, as well as experimenting with different technologies and approaches. Overall, the analysis of the data suggests that, after the pandemic and with due preparation and support, some of the digital technologies and approaches experimented with will be incorporated into pedagogical practices in blended approaches, which represent a real trend and possibility for language teaching in the post-pandemic context.
\end{abstract}

Keywords: Online Language Teaching and Learning, Covid-19, pandemic, teachers' perceptions

\section{Introduction}

The Covid-19 pandemic changed many of our social practices, imposing physical/ social distancing measures that impeded face-to-face interactions, thus forcing many activities to migrate to online environments (Henrique, 2020). This was done in order to enhance social connectedness so as to counter the feelings of loneliness, isolation, anxiety and even depression caused by the absence of social interactions during lockdown (Moore and March, 2020). Professional practices have also been affected by the pandemic and teachers were no exception: they were forced to migrate to online teaching, in some cases, overnight and without any specific training or preparation. The exceptional situation we have experienced since then has forced many language teachers to implement activities either in emergency remote/online teaching or in the distance learning format.

Emergency remote/online teaching is a temporary solution for the continuation of pedagogical activities (online) and it should not be confused with distance learning. The latter is an umbrella term (Moore and March, 2020; Keegan, 1996) used to refer to an educational modality with its own pedagogical design to cover contents, tasks and student evaluation with specific teacher training and support from tutors as well as specific technological resources. Initially, the term "distance learning" highlighted the constraints associated with "distance", such as time and place (Guilar and Loring, 2008; Newby et al., 2000). However, its meaning evolved to describe other forms of learning, such as online learning, e-Learning, technology-mediated learning, online collaborative learning, virtual learning, and web-based learning, among others (Conrad, 2006). 
In a recent article, Castells (2020) ${ }^{1}$ suggests that the current pandemic has highlighted what was already happening, that is, we were already living in the digital society in many ways. The social distancing measures imposed by the pandemic have made us become physically distant though virtually closer, showing that the Internet can serve to either connect or isolate/alienate individuals in this new reality or 'virtuality'.

Castells (2020) also warns us that there will be no setback in this new digital society, since the new normal will not be what we knew before, but a new reality that is also virtual. Based on data from 2019, this author reports that $91.4 \%$ of households in Spain have access to the Internet through a computer, and in the case of families with at least one young person, these figures increase to 93.3\%. Regarding access to smartphones in the same report, $97 \%$ of people in Spain have cell phones, $87 \%$ of which are smartphones, meaning they have a computer with Internet access in their pocket or the palm of their hand.

In the case of Brazil, where most of the respondents from this study come from, the Brazilian Institute of Geography and Statistics (IBGE) reports that in 2019 the Internet was used in 82,7\% of households, showing a 3.6 increase in relation to 2018. Yet, it is important to note that most of these households with Internet access are located in urban centers. Nevertheless, the most recent data available from $\mathrm{IBGE}^{2}$ shows that the growth in Internet connection was more significant in rural areas, raising from $49.2 \%$ in 2018 to $55.6 \%$ in 2019 . This increase corresponds to $6.4 \%$, whereas in urban households it rose from $83.8 \%$ in 2018 to $86.7 \%$ in 2019 .

More recently, in a survey carried out during the pandemic at the Federal University of Espítrito Santo in Brazil, it was found that only about three quarters of the students had adequate conditions to participate in remote/ online classes. In this sense, and even though Castells (2020) refers mainly to the Spanish context in his article, making some references to Latin America, it is important to bear in mind the social inequalities that increase the digital divide, thus affecting online teaching/learning. In Brazil, the social / digital divide became more evident during the pandemic, when people from lower socio-economic classes struggled to cash in government financial support to mitigate the effects of the pandemic, since those funds could only be requested through the national bank app via smartphones.

Still, according to data from 2019 reported by Castells (2020), people spend an average of 5.5 hours per day online. In other words, online communication/interaction was part of our lives before the pandemic, making the transition to online activities during lockdown less dramatic. However, this does not mean that the transition to online activities is less complex or challenging, especially if we consider the different contexts where this transition to remote/online teaching and learning took place.

Regarding teacher preparation to deal with the mediation of technology in this new reality, several studies have already shown (see, for example, Mendes \& Finardi, 2018; Fadini, 2016; and Macedo, 2017 for Brazil; and Kessler \& Hubbard, 2017 and Masterson, 2020 in general) the lack of specific teacher training for the integration of digital technologies into pedagogical practices. The social distancing measures imposed by the pandemic have challenged and decentralized the teaching/learning processes, breaking the walls, curricula, and routines of educational institutions and parties involved.

The "global" pandemic is also very "local" in the sense that, depending on the context in which each person experiences it, its impact may be perceived in a completely different way (see, for example, Moorhouse, 2020 in Hong Kong, Assunção Flores \& Gago, 2020 for Portugal, and Hoenig \& Wenz, 2020 for Germany). French philosopher Morin (2000) reminds us of the importance of connecting parts to the whole and vice-versa in education. His reflection, coupled with our interest in delving into how language teachers dealt with local and global challenges to overcome the effects of the disruption of classes caused by the pandemic using technologies in remote/online approaches to build / develop a (new) teaching-learning mode, is what motivates this study.

Having outlined this panorama, the present study aims to contribute to this reflection by offering a glimpse of how language teachers in different contexts around the world are facing the challenges imposed by the

\footnotetext{
Castells, M. (2020). O digital é o novo normal [Digital is the new normal]. https://www.fronteiras.com/artigos/o-digital-e-o-novo-normal?fbclid=IwAR1iTxx5DuuO-wpo4CFM3a6IeCsfgk5GLOZ6CpGxbL6gjZSaicpLLvI0Hng

2 Pesquisa mostra que $82,7 \%$ dos domicílios brasileiros têm acesso à internet [Research shows that $82.7 \%$ Brazilian homes have internet access].https://www.gov.br/mcom/pt-br/noticias/2021/abril/pesquisa-mostra-que-82-7-dos-domicilios-brasileiros-tem-acesso-a-internet\#: :text=Em\%202019\%2C\%20entre\%20as\%20183,estudantes\%20(75\%2C8\%25)
} 
pandemic, thus helping us to prepare for a new reality. With that aim, the methodology used for analyzing the perceptions of language teachers in Brazil, Spain, France, Cyprus, Costa Rica and Taiwan is described, as well as the corresponding findings.

\section{Methodology}

\section{Participants}

A total of $76(\mathrm{~N}=76)$ participants took part in the study. Out of those, the $64(\mathrm{n}=64)$ participants from the Brazilian group were language teachers in Brazil. Meanwhile, the $12(\mathrm{n}=12)$ participants from the international group were language teachers in Spain, France, Cyprus, Costa Rica and Taiwan. All of them were aged between 30 and 55 and had various levels of teaching experience.

8 participants $(\mathrm{N}=8)$ out of the 76 questionnaire respondents were subsequently randomly selected and invited to take part in the focus groups discussions. Out of those, 4 were Brazilian and 4 were from the following countries: France, Cyprus and Spain. In the Brazilian focus group, participant A is an English teacher who runs her own business; participant B is an English teacher with an open language learning course focusing on Business English and English for Specific Purposes; and participants C and D are both private English teachers. In the international group, participants $\mathrm{A}$ and $\mathrm{C}$ are English for Specific Purposes lecturers in public higher education institutions in France and Cyprus respectively; participant B is an English language lecturer in a public higher education institution in Spain and participant D is a teacher-training lecturer in a public higher institution in Spain who has experience as a teacher of Spanish as a Foreign Language.

\section{Research Design}

The research question motivating the study is: what are language teachers' perceptions regarding remote/ online teaching during the pandemic? The approach employed to analyze the data was qualitative, contrasting data from the questionnaire shared in an asynchronous online form with data from the focus group interviews, which were carried out synchronously. The context of the study is foreign language teaching (mostly English except for one Spanish participant who was a teacher-training lecturer with experience in teaching Spanish as a Foreign Language) in Brazil, Spain, France, Cyprus, Costa Rica and Taiwan.

\section{Procedure}

In the first phase, the online questionnaire (APPENDIX A) with 12 questions was shared on social networks and via email with the purpose of analyzing the use of digital technologies for teaching during the pandemic. It was answered between September and October 2020 by 64 Brazilian language teachers (APPENDIX B), and by 12 language teachers in Spain, France, Cyprus, Costa Rica and Taiwan. The responses to the questionnaire were discussed in Portuguese with a group of four Brazilian teachers who also participated in a focus group interview, as well as with 4 teachers in Spain, France and Cyprus in another focus group interview carried out in English. The focus group interviews were carried out online in Zoom and Blackboard Collaborate in November 2020. Once the analysis of the questionnaire responses was completed, the next phase took place: 8 of the questionnaire respondents were randomly selected and invited to participate in semi-structured interviews in the form of focus group discussions via Zoom in Portuguese (in the case of the Brazilian participants) and Blackboard Collaborate in English (in the case of the participants from Spain, France and Cyprus) so as to allow for more in-depth discussions of the issues raised in the questionnaire.

\section{Analysis}

The results of the questionnaires and focus groups conducted with the Brazilian and international participants were contrasted and analyzed qualitatively by the two researchers, discussing similarities, differences and also trends in the data. In the initial stages of the data analysis process, inter-rater reliability was achieved by means of a discussion of the analysis framework and the subsequent coding of $25 \%$ of the data. This was followed by a cycle of comparing results and ensuring there were not any inconsistencies. Furthermore, Cohen's kappa coefficient $(\kappa)$ was used to measure inter-rater reliability (as well as intra-rater reliability) regarding the 
analysis of the data from both the Brazilian and the international groups. Given that there was very strong agreement between the two raters, $\kappa=1.000, \mathrm{p}<.0005$, the categories were agreed upon and one of the researchers coded both data sets.

\section{Results}

\section{Brazilian Teachers}

Regarding the geographical distribution of the 64 Brazilian respondents, they came from nine Brazilian states. Most of them (65.6\%) were from Espírito Santo (ES). In addition, 17.2\% were from Rio de Janeiro (RJ), 1.6\% from São Paulo (SP), 6.3\% from Bahia (BA), 1.6\% from Alagoas (AL), 1.6\% from Amazonas (AM), 3.1\% from Goiás (GO), 1.6\% from Rio Grande do Sul (RS) and 1.6\% from the Federal District (DF). Furthermore, almost half of them worked in open language learning courses (39.1\%), 32.8\% of which were private and $29.7 \%$ of which were public. It is important to highlight that the states of ES, RJ, SP are located in the Southeast region of Brazil, which is the most populated, urban and rich region in the country.

More than half of the Brazilian respondents (53.1\%) had worked in their current educational institution for over 5 years, $18.8 \%$ had worked there between 5 and 10 years, $14.1 \%$ between 11 and 15 years, $4.7 \%$ between 16 and 20 years, and $9.4 \%$ had worked there for over 20 years. Therefore, we can say most of the Brazilian teachers had some sort of institutional stability or job seniority before the pandemic disrupted their teaching.

In regard to their experience with remote/online teaching, almost half of the Brazilian respondents (43.8\%) were teaching only online, while $34.4 \%$ were teaching partially online and $21.8 \%$ were not teaching online at all.

Regarding their experience with online teaching, a considerable number of Brazilian respondents (23.4\%) said they had taught online or had been implementing online activities even before the pandemic. Almost half of them (43.8\%) claimed to have been teaching online or implementing online activities for over a month, while $25 \%$ stated they had been teaching online for less than a month at the time of data collection.

More than half of the Brazilian respondents (56.3\%) had never taught online before the disruption caused by the pandemic, while $29.7 \%$ had taught online before. Meanwhile, $12.5 \%$ had used blended/hybrid approaches, doing most of the teaching in a face-to-face/in-person format, combined with some online activities.

In terms of their feeling of preparation to teach online, 37.5\% of the Brazilian respondents said they did not really feel prepared for the experience of remote/online education, while $29.7 \%$ felt prepared and $20.3 \%$ felt unprepared to teach in this modality. The rest of Brazilian respondents declared being in the adaptation phase, receiving guidance, investing in equipment and / or training, or learning from their own practice. Furthermore, $34.4 \%$ were teaching online asynchronously, $25 \%$ were teaching synchronously and $32.8 \%$ were doing both.

Most respondents (76.6\%) considered that their workload had increased, as they needed to prepare online contents, though $21.9 \%$ thought it was possible to organize the materials better since, according to $31.3 \%$ of the respondents, it had become necessary to provide an introduction for each unit, as well as explain in more detail how to use online materials and resources. In addition, 53.1\% mentioned the need to provide even more specific instructions during online teaching, and 34.4\% highlighted the need to provide students with an activity template. Finally, less than $2 \%$ of the respondents were working online with the same textbook they had been using in their face-to-face/in-person classes.

The most widely used platform was Zoom (54.7\%), followed by Google Classroom (37.5\%), Google Meet (23.4 \%) and Moodle (15.6\%), though other applications or social networks, such as Skype, YouTube, WhatsApp, institutional e-mail or even a website created by the educational institution were mentioned, but to a much lesser extent. Almost half of the respondents (48.4\%) used pre-recorded videos for the first time (asynchronous), followed by video conferencing (synchronous), which was also used for the first time by $37.5 \%$ of respondents. $17.2 \%$ said they used digital audio recordings for the first time, $21.9 \%$ mentioned using chats, $15.6 \%$ used forums, $29.7 \%$ used screen recordings and $26.6 \%$ said they had already worked with all these tools before the 
pandemic. Other options, such as WhatsApp, Moodle, social media posts, live Instagram videos, Google Slides, ActivInspire (digital whiteboard), were selected by only one Brazilian respondent in each case.

The analysis of the answers to the question: 'how did you adapt to these changes?' showed that out of the 64 responses, only 10 respondents expressed a positive view of the process of adapting to online teaching. Meanwhile, 15 respondents expressed a negative view of this adaptation process, motivated by the lack of training and institutional support for it. Most of the respondents who expressed negative views about online teaching had never taught in this format before (56.3\%), and $37.5 \%$ claimed to lack preparation for this adaptation.

Of the 64 Brazilian respondents, 19 mentioned the need for more qualification, training and support. However, only three of them specified that in their opinion this should be provided by the institution, perhaps indicating that they resented the fact that they had to look for training and solutions for online teaching on their own by means of tutorials, online courses and publications.

The analysis of the answers to the question: 'what is the genre (chat, forum, video conferences, audio conferences, webinars, etc.) that you have used the most to teach online and why?' showed that of the 64 Brazilian respondents, 33 used videoconferences. 11 of them chose this resource due to its advantages (interaction, dynamism, variety of functionalities), and five used video conferences because of the institutional policy. Furthermore, 10 respondents said they used online chat to answer students' questions, or because it is the easiest and simplest way to communicate with students, due to the fact that many students do not have access to a data package that allows them to use video conferences, for example. Four respondents stated they used online forums, combined with other tools, 10 respondents said they used different tools (whether synchronous or asynchronous) to teach online, and nine respondents stated that they used recorded videos because they provide students with greater flexibility in terms of schedules and activities.

The analysis of the answers to the question 'how do you intend to use some of these activities or genres in the future after social isolation is lifted?' showed that 38 respondents intended to continue using online tools to supplement their face-to-face/in-person classes, namely Google-based tools. Seven of these said they expected to continue using "Google Classroom" and "Google Forms" in blended/hybrid approaches after the pandemic. Perceptions about blended/hybrid teaching were mixed: 6 respondents showed some resistance towards it, arguing that they did not intend to use online tools again after the lockdown ended because of a perceived lack of support and preparation on the part of the institutions in which they worked. Meanwhile, 6 other teachers expressed their eagerness to blend their classes after the pandemic.

\section{International Teachers}

The participants from the international group were 12 teachers of Spanish, French, Cypriot, Costa Rican and Taiwanese nationality. This means that 3 continents were represented in the sample: Asia, America, and Europe. All participants in this group were working in higher education institutions, $70 \%$ of which were public while the remaining $30 \%$ were private.

Most participants in this group (seven out of 12) had been working in their institution for less than 5 years, one participant had between 5 and 10 years of experience in that institution, 2 participants had worked there for between 11 and 15 years and the 2 remaining participants had worked in their current institution for over 16 years.

In addition, four participants were currently teaching fully online, six participants were partially teaching in an online modality and two participants were not teaching online at all. Regarding their experience with online teaching, five participants had over one year of experience teaching online, whereas the remaining seven international teachers had only months or even weeks of experience with online teaching. Furthermore, 10 participants had had previous experiences teaching online, whereas for two of them this was their first online teaching experience. Among them, eight teachers felt 'well prepared' and four teachers felt 'somewhat prepared'. None of them felt 'unprepared'. Most of the participants (80\%) were teaching in a blended mode, using a combination of synchronous and asynchronous activities. When asked about how online/blended teaching had affected their methodology, $80 \%$ of respondents said they provide specific instructions for each online/blended 
activity, eight of them said that they could now better organize their materials even though their workload had increased. Meanwhile, five responded that gave an introduction to each unit and three provided a template for each activity.

When asked about how they had adapted to those changes, only one international teacher showed a negative reaction to online teaching, which had caused this participant to abandon this teaching modality. The rest of the participants displayed a more positive attitude towards online teaching and said they had attended training sessions and specific courses on online/blended teaching. In addition, they had explored new apps that had helped them enrich their teaching.

As for the most frequently used apps and tools for online/blended teaching among the international teachers who participated in the study, 70\% used Moodle, 70\% used Microsoft Teams, 20\% used Blackboard Collaborate and Google Classroom, 40\% used Google Meet and Zoom, and 1\% used Adobe Connect. Additional tools mentioned by participants included Kahoot, Mentimeter, Jamboard, and Mural.co, which were said to be used to make their lessons more engaging and dynamic.

\section{Brazilian Teachers Focus Group Interview}

The aim of the focus group interview was to expand the responses to the questionnaire. Most Brazilian teachers expressed a concern for interaction in the online mode, highlighting the fact that not all students had their cameras and microphones on during the lessons, thus making interaction (and evaluation) challenging for teachers. Brazilian teachers working in private language schools and other educational contexts reported feeling pressured to migrate to the online teaching mode without due preparation or institutional support for that transition. Also, teachers working in public institutions feared the reduction of government financial support to public education resulting from the transition to the online mode.

\section{International Teachers Focus Group Interview: Spain, France, and Cyprus}

The participants from the international group who took part in the focus group interview reported having had some negative experiences connected to either some of the students' inability to use their computers' cameras and/or microphones during the online lessons or their unwillingness to switch on those devices. In those cases, the classes were said to feel like a monologue rather than the interactive, participatory, dynamic classes they are/were used to when their classes are/were taught in face-to-face/in-person formats. An additional challenge reported by one of the interviewees had to do with the fact that when his lessons were streamed live in a dual mode $^{3}$, the students following the class from home would only have access to the audio without the teacher's image or body language, which caused some comprehension difficulties and challenged interaction.

Changes in teaching methodologies were also discussed during the focus group interview. Participants reported having had to adjust their teaching to the new teaching modalities (online, blended or dual) and one of them highlighted the fact that his classes had to be more structured now so that students would not feel lost, which was positive in a way but also reduced the room for spontaneity and creativity. The respondent from Cyprus claimed that methodologies had not changed (they were still task-based, project-based, and student-centered), it was only the medium (online) that had changed, though that medium imposed new challenges, especially in terms of how to enable interaction (limited to break-out rooms in Zoom, mostly) and carry out exams.

As for the workload, all but one focus group participant felt that their workload had increased due to the hybrid/ dual/online teaching modalities brought about by the pandemic. The reason why one participant felt that her workload had actually decreased was that students worked autonomously and did not ask for help when they encountered any problems, preferring to try and solve them by themselves instead. One of the participants reported feelings of excitement about the opportunity to put into practice during this pandemic the online teaching training she had received, in spite of the difficulties caused by the lack of technical support provided by her institution.

\footnotetext{
3 The dual mode, used by some institutions to reduce the number of in-person students,was used by some teachers whereby they would be in class teaching some students face-to-face while other students would be online following the streaming in such a way that half of the students would be online while the other half would face-to-face, in a rotating system.
} 
As far as the tools are concerned, the interviewees reported having experimented with and used some new tools during the pandemic, many of which they plan to continue using after the pandemic. These tools, most of which were videoconferencing tools, included Moodle and its adaptations to different institutions, Microsoft Teams, Zoom and Blackboard Collaborate, as well as other tools like Kahoot, Mentimeter, Jamboard and Mural. co.

Though most of the international respondents in the second focus group interview showed overall positive attitudes towards online teaching and the changes brought about by the pandemic, as well as to the pivot to remote/online teaching modalities, fears were expressed with regard to the impact of the pandemic on teacher education and the profession, as well as on the value given to languages in general and foreign language teaching in particular. In other words, teachers were concerned about the fact that politicians might take advantage of the changes brought about by the pandemic and use the switch to remote/online learning modalities as an excuse to cut down the amount of teaching jobs while worsening the conditions of teachers, who could even be replaced by teaching assistants in charge of moderating online discussions. An additional point raised by the teachers, maybe to counterbalance the aforementioned argument, was that it would be extremely difficult to replace the teachers in the classroom, as the quality of the teacher-teacher and teacherstudents interactions is considered to be higher in face-to-face/in-person contexts than in remote/online learning contexts. Furthermore, international teachers reported that, in general, students found it easier to stay focused and to follow the lessons when they were face-to-face, in addition to the experience being more enjoyable. This was considered to be so because when students follow the lessons online they have many distractions, they might experience technical difficulties and they miss the direct contact with and closeness to their classmates and their teacher.

\section{Discussion}

The results in the Brazilian case showed that most respondents had a negative attitude towards the move to emergency remote/online education, since they had no choice and had to adapt to it too quickly, revealing lack of preparation by teachers and students besides the lack of support and investment in training from educational institutions. The greater speed with which private schools switched to remote/online teaching when compared to public institutions in Brazil is evidence of the market forces behind this movement. This was expressed in our data in what concerns the fear expressed by some teachers regarding cuts in investments in public education and the migration of investments from teaching jobs to technologies. Meanwhile, the international teachers seemed to have more positive attitudes towards remote/online teaching, even though they also pointed out some negative aspects, connected to the lack of institutional support and the concern politicians might make this emergency teaching the norm rather than the exception to reduce the amount of teaching jobs offered while worsening the teaching conditions.

On the other hand, an enormous effort on the part of the teachers was perceived to adapt to the new modality / reality / "virtuality". In this sense, and according to Castells' (2020) suggestion that the pandemic came to consolidate what had already started in our daily practices with online tools, studies on hybrid/blended language teaching in Brazil as well as teacher training for the integration of ICT into language education suggest that blended approaches in Brazil and beyond are here to stay. Nevertheless, more teacher education and institutional support are required to prepare teachers for this new reality while counteracting the negative experiences of teachers when teaching online during the pandemic.

Regarding how the data in this study may relate to the global context, the UNESCO/IAU Global Survey Report published by Marinoni et al. (2020) is worth mentioning. In this report, 424 replies to a survey that included 109 countries were analyzed. In the survey, Africa and Europe were overrepresented while the Americas and Asia were underrepresented. The analysis shows that most institutions were affected by the pandemic, though Africa was affected to a greater extent, with $77 \%$ of institutions closed across the continent, as opposed to nearly $20 \%$ in other regions. In the case of the current study, all the Brazilian public institutions closed, at least for a few months, until they were able to switch to remote/online teaching. Meanwhile, most of the other institutions where the international teachers in this study worked did not close, placing Brazil somewhat in the middle between Europe and Africa in terms of the effects of the pandemic on closing institutions. 
Another finding of the aforementioned report that may be seen in relation to data in our study is the fact that almost half of the survey respondents reported having government support to mitigate the disruption caused by the pandemic. Meanwhile, this scenario was somewhat different in the case of the Brazilian respondents, who feared that the government would take advantage of the need to go online to reduce salaries and investment in public education.

In terms of the effects of the pandemic on teaching and learning processes, the report shows that two thirds of the institutions replaced face-to-face/in-person classes with online/distance learning. The main challenge found in this transition had to do with infrastructure and pedagogies for this mode of teaching/learning. In this sense, the data from the aforementioned report mirror the one analyzed in the present study.

Though this study did not follow a mixed-methods design, unlike Maican and Cocorada's (2021), nor did it follow the same validation testing procedure found in Crisol et al.'s (2020), these studies have a common view. This shared perspective is connected to the United Nations' Sustainable Development Program for 2030, which establishes principles for sustainable action that take up the form of Sustainable Development Goals (SDGs). Regarding the fourth of those goals, "Quality and inclusive education", the pandemic has affected the delivery of education worldwide to a point that education (in the case of the present study, foreign language education), may become only available to a privileged few. Moreover, as put forward by Maican and Cocorada (2021), online foreign language learning during the pandemic represents a way to adapt to the restrictions imposed worldwide. Despite Castell's (2020) analysis of the "new normal", comparing Spain to Latin America, results of the present study, whose largest populations came from Brazil and Spain, respectively, suggest that Spanish (and international) teachers felt more prepared than Brazilians for the pivot to emergency remote/online teaching.

\section{Conclusion}

The emergency nature of the actions taken by educational institutions should be highlighted. Given the almost immediate presentation of "contingency/emergency plans" for the pandemic, the lack of time to adjust to those drastic changes may have provoked an adverse reaction in Brazilian teachers and students.

Overall, the analysis of the questionnaire data showed that the vast majority of teachers used different digital technologies to teach online, both synchronously and asynchronously, but felt unprepared (mostly the Brazilians) to work in this modality because of the lack of institutional support and training for this modality. The analysis of the focus group interviews suggests that most Brazilian and some international teachers displayed negative attitudes towards emergency remote/online teaching due to the lack of preparation and institutional support for this modality and also because of concerns for the political implications of online education in the case of Brazil and some other countries, which could result in the precariousness of the teacher profession.

Overall, the analysis of the data suggests that after the pandemic and with due preparation and support, some of the digital technologies and approaches experimented with during emergency remote/online teaching will be incorporated into pedagogical practices in blended/hybrid approaches, which represent a real trend and possibility for language teaching in the post-pandemic context.

\section{Acknowledgments}

Acknowledgements are due to Valencia's regional government, Generalitat Valenciana, for funding the project YES3D: Youth Entrepreneurship for Society in 3D (Ref. GV/2021/179) for the period 01/10/2021 to 31/12/2022, which has supported this research study.

Acknowledgements are also due to the Spanish Ministry of Science, Innovation and Universities for funding the research project VELCOME: Virtual exchange for learning and competence development in EMI classrooms (Ref: RTI2018-094601-B-100), for the period 2018-2021, which has also supported this research study.

Acknowledgements are due to the Brazilian National Research Council (CNPq) for Dr. Kyria Finardi's Research Productivity Grant Level PQ2 


\section{Declaration of Competing Interest}

None declared.

\section{References}

Assunção Flores, M., \& Gago, M. (2020). Teacher education in times of Covid-19 pandemic in Portugal: National, institutional, and pedagogical responses. Journal of Education for Teaching, 46(4), 507-516. https://doi.org/1 $0.1080 / 02607476.2020 .1799709$

Conrad, D. (2006). E-Learning and social change: An apparent contradiction. In. M. Beaudoin (Ed.), Perspectives on higher education in the digital age (pp. 21-33). Nova Science Publishers.

Crisol Moya, E., Molonia, T., \& Caurcel Cara, M. J. (2020). Inclusive leadership and education quality: Adaptation and validation of the questionnaire "Inclusive Leadership in Schools" (LEI-Q) to the Italian context. Sustainability, 12(13), 1-17. https://doi.org/10.3390/su12135375

Fadini, K. A. (2016). Formação Inicial de Professores de Inglês do e para o Século XXI: Os papéis da língua inglesa e da tecnologia digital [Initial English Teacher Education in and for the XXI century: the role of English and digital technologies] [Unpublished master's dissertation]. Universidade Federal do Espírito Santo.

Guilar, J., \& Loring, A. (2008). Dialogue and community in online learning: Lessons from Royal Roads University. Journal of Distance Education, 22(3), 19-40.

Henrique, T. (2020). Covid-19 e a internet (ou estou em isolamento social físico) [Covid-19 and the internet (or I am in social physical distancing)]. Interfaces Científicas - Humanas e Sociais, 8(3), 173-176. https://doi. org/10.17564/2316-3801.2020v8n3p5-8.

Hoenig, K., \& Wenz, S. E. (2020). Education, health behavior, and working conditions during the pandemic: Evidence from a German sample. European Societies, 23(Suppl. 1), 275-288. https://doi.org/10.1080/1461669 6.2020 .1824004

Kessler, G., \& Hubbard, P. (2017). Language teacher education and technology. In Carol A. Chapelle, \& Shannon Sauro (Eds.), The handbook of technology and second language teaching and learning (pp. 278-292). John Wiley \& Sons, Inc. https://doi.org/10.1002/9781118914069.ch19

Keegan, D. (1996). Foundations of distance education (3rd ed.). Routledge.

Macedo, A. R. (2017). Abordagem Híbrida na Formação Inicial de Professores de Inglês: Integrando as Novas Tecnologias [Hybrid approach in Initial English language teaching education: Integrating the new technologies] [Unpublished doctoral dissertation].Universidade Federal do Espírito Santo.

Mendes, A. R.; Finardi, K. R. (2018). Linguistic education under revision: Globalization and EFL teacher education in Brazil. Education and Linguistics Research, 4(1), 45 - 64. http://doi.org/10.5296/elr.v4i1.12831

Maican, M. A., \& Cocorada, E. (2021). Online foreign language learning in higher education and its correlates during the Covid-19 pandemic. Sustainability, 13(2), 1-21. https://doi.org/10.3390/su13020781

Marinoni, G., Van't Land, H., \& Jensen, T. (2020). The impact of Covid-19 on higher education around the world. IAU Global Survey Report. International Association of Universities.

Masterson, M. (2020). An exploration of the potential role of digital technologies for promoting learning in foreign language classrooms: Lessons for a pandemic. International Journal of Emerging Technologies in Learning, 15(14), 83-96. http://dx.doi.org/10.3991/ijet.v15i14.13297

Moore, K., \& March, E. (2020). Socially connected during Covid-19: Online social connections mediate the relationship between loneliness and positive coping strategies. Research Square [Preprint]. https://doi. org/10.21203/rs.3.rs-35835/v1

Moorhouse, B. L. (2020). Adaptations to a face-to-face initial teacher education course forced online due to the Covid-19 pandemic. Journal of Education for Teaching, 1(3), 609-611. https://doi.org/10.1080/02607476.2020 .1755205

Morin, E. (2000). Os sete saberes necessários à educação do future [The seven necessary knowledges for future education] (2nd ed.). Edgard de Assis Carvalho.

Newby, T., Stepich, D., Lehman, J., \& Russell, J. (2000). Instructional technology for teaching and learning: Designing instruction, integrating computers, and using media (2nd ed.). Prentice-Hall.

Stuart, J., O’Donnell, K., O’Donnell, A., Scott, R. \& Barber, B. (2021). online social connection as a buffer of health anxiety and isolation during Covid-19. Cyberpsychology, Behavior, and Social Networking, 24(8), 521525. http://doi.org/10.1089/cyber.2020.0645 


\section{APPENDIX A}

\section{DISTANCE TEACHING QUESTIONNAIRE}

Distance/Remote Language Teaching Questionnaire

Distance/Remote Language Teaching

Questionnaire

Dear teacher,

The exceptional situation we are experiencing today has prompted many educators and institutions to implement online/remote/blended learning activities. We would like to know your experience lived in this unusual situation, as well as investigate the development of new teaching practices and so we kindly ask that you answer the questions below, which should take less than 10 minutes. We greatly appreciate your participation.

*Required

Before you answer the questions...

Before you answer the questions, please check/tick the "informed consent" box below.

1. INFORMED CONSENT * (Check all that apply.)

INFORMED CONSENT: In answering this questionnaire, I authorize its authors to use my personal information for research purposes, in a confidential manner, for the protection of personal data and the guarantee of digital rights.

2. Level you teach (check option) * (Mark only one oval.)

$\square$ Public primary education

$\square$ Private primary education

$\square$ Public secondary education

$\square$ Private secondary education

Public higher education

$\square$ Private higher education

Free courses

Other:

3. Region/City or town where you work: *

4. Number of years you have worked at this educational institution * (Mark only one oval.)
$\square$ Less than 5
$5-10$
$11-15$
$16-20$
More than 20
$\square$ Other:

5. Are you involved in online/remote/blended teaching at the moment? * (Mark only one oval.)

$\square$ Yes, totally.

$\square$ Yes, partially.

$\square$ No.

Other:

6. How long have you been teaching or implementing activities in the online/remote/blended format?

7. Had you taught in the online/remote/blended format before? * (Mark only one oval.)

$\square$ Yes

$\square$ No

8. How do you feel about this experience? * (Mark only one oval.)

$\square$ Well prepared

Somehow Prepared

Unprepared 
9. Are you teaching synchronously (e.g. video conference: students attend virtual classes at the same time you teach) or asynchronously (recorded videos and online materials that students can access at any time)? Select the option (s). * (Check all that apply.)

$\square$ Synchronously

$\square$ Asynchronously

$\square$ Both

Other:

10. How has your teaching methodology changed? Select the option (s). * (Check all that apply.)

$\square \quad$ Now I can better organize the materials

$\square \quad$ I provide an introduction for each unit or class explaining how to use the materials

$\square \quad$ I provide specific instructions for each activity

I provide a template for all activities

$\square \quad$ My workload has increased because of having to prepare online content

$\square$ Other:

11. How have you adapted to these changes?*

12. What platform or application have you used to teach online? Select the option(s). * (Check all that apply.)

$\square$ Moodle

$\square$ WebEX

$\square$ Blackboard Collaborate

$\square$ Google Classroom

$\square$ Google Meet

$\square$ Zoom

$\square$ Microsoft Teams

$\square$ Other: 


\section{APPENDIX B}

\section{FOCUS GROUP INTERVIEW SCRIPT}

1. Request authorization from participants to record the session;

2. Explain to the participants that our intention is to elaborate a little more on their answers from the questionnaire used in the quantitative data analysis so as gain qualitative insight into the data;

3. Present the quantitative data to the participants and ask them to answer/discuss the following questions:

Question 1: $\quad$ How do you feel about this experience (teaching online)?

Question 2: How has your teaching methodology changed?

Question 3: How did you adapt to these changes?

Question 4: How do you intend to use the activities and tools you used during the pandemic in the future after social isolation is lifted? 